\title{
Respiratory diseases in children and outdoor air pollution in São Paulo, Brazil: a time series analysis
}

\author{
Nelson Gouveia, Tony Fletcher
}

\begin{abstract}
Objectives-To investigate the short term effects of air pollution on the respiratory morbidity of children living in São Paulo, Brazil, one of the largest cities in the developing world.

Methods-Daily counts of hospital admissions due to respiratory diseases along with daily levels of meteorological variables and air pollutants $\left(\mathbf{P M}_{10}, \mathbf{S O}_{2}, \mathbf{N O}_{2}\right.$, $\mathrm{O}_{3}$, and $\left.\mathrm{CO}\right)$ were analysed with Poisson regression. Final models were adjusted for the effects of time trends, seasonal patterns, weekdays, holidays, meteorological factors, and serial correlation.

Results-Daily admissions of children to hospital for total respiratory disease and pneumonia showed significant increases associated with $\mathrm{O}_{3}(5-8 \%), \mathrm{NO}_{2}(9 \%)$, and with $\mathbf{P M}_{10}(9 \%)$ (results are for an increase from the 10th to the 90th percentile of pollution measurements). Consistently, effects for pneumonia were greater than for all respiratory diseases combined. Also, effects on infants (children $<1$ year old) presented higher estimates. Similar associations were found for asthma admissions. Point estimates for most pollutants were higher for asthma than for other diagnosed admissions. However, these associations were not significant.

Conclusions-These results agree with the limited publications on this subject but indicate a rather smaller magnitude of effects. Nevertheless, given the present concentrations of air pollution in São Paulo and the large population potentially exposed attention should be directed to minimise such effects.

(Occup Environ Med 2000;57:477-483)
\end{abstract}

Keywords: air pollution; hospital admissions; respiratory diseases in children

Departamento de Medicina Preventiva, Faculdade de Medicina da Universidade de São Paulo, Av Dr Arnaldo 455, Sao Paulo 01246-903, SP, Brazil

$\mathrm{N}$ Gouveia

London School of Hygiene and Tropical Medicine, London, UK

T Fletcher

Correspondence to: Dr Nelson Gouveia ngouveia@usp.br

Accepted 26 January 2000 associations between urban concentrations of air pollution and mortality for respiratory diseases. $^{4-8}$ These results, however, were for sure to outdoor concentrations of air pollution has been pointed out as possibly being one of them. ${ }^{1}$

Several studies have reported significant mortality in all ages or in elderly people. There is much less evidence of such an association with mortality in children. On the other hand, different aspects of respiratory morbidity in children have been described as associated with outdoor air pollution. For example, changes in pulmonary function, ${ }^{9-12}$ absence from school due to respiratory conditions, ${ }^{13}{ }^{14}$ and recorded episodes of illness or symptoms. ${ }^{15-18}$ Also, few studies found significant associations between concentrations of air pollutants and hospital admissions for respiratory diseases in children. ${ }^{19-21}$

Studies of daily admissions to hospitals have the advantage of making possible the examination of acute relations with daily variations in air pollution. However, there are still few studies on hospital admissions to date that have presented results for children. Most of these studies were conducted in developed countries where concentrations of air pollution, climatic conditions, and many other factors are very different from those of most developing countries. Moreover, results of these studies have generally been less consistent than for mortality. Effect size and the pollutants involved varied considerably between publications.

This study is an attempt to investigate the effect of exposure to outdoor concentrations of air pollution and the occurrence of hospital admissions for respiratory diseases in children $<5$ years old in one of the largest cities of the developing world.

\section{Methods}

This study covered a period of 23 months (November 1992 to September 1994) and was carried out in the city of São Paulo, the most urbanised, industrialised, and affluent city in Brazil. The population of São Paulo, according to the 1991 national census, was 9.5 million inhabitants.

Data on hospital admissions were available from computerised files of the Health Services Information Database of the Brazilian Unified Health System (SUS). This system covers about $66 \%$ of all admissions to the 150 hospitals in the city of São Paulo (M Lebrao, personal communication) and provides information on date of birth, age, and sex, date of admission and discharge, how many days were spent in intensive care, the main diagnosis for the admission (coded according to international classification of diseases, 9 th revision: ICD-9), and whether the patient died or not after admission, besides other information.

The outcomes selected for this study were hospital admissions for all respiratory diseases (ICD-9 chapter VIII), pneumonia infections 
(ICD-9 codes 480-486), and asthma or bronchitis (ICD-9 codes 466, 490, 491, 493) for children $<5$ years of age. Also, admissions due to pneumonia infections were examined for children $<1$ year of age. Hospital admissions were defined as stays of at least 24 hours in a hospital bed. Admissions of children $<28$ days old (neonatal) are strongly influenced by perinatal conditions and therefore, were not included in this analysis.

Data on air pollution were available from CETESB, the environmental agency in São Paulo. These data comprised daily values of sulphur dioxide $\left(\mathrm{SO}_{2}\right)$, respirable particles $\left(\mathrm{PM}_{10}\right)$, nitrogen dioxide $\left(\mathrm{NO}_{2}\right)$, carbon monoxide $(\mathrm{CO})$, and ozone $\left(\mathrm{O}_{3}\right)$. Data on $\mathrm{PM}_{10}$ and $\mathrm{SO}_{2}$ were available for 12 and 13 monitoring stations respectively. Other pollutants were only collected in five $\left(\mathrm{O}_{3}\right)$ or four $\left(\mathrm{NO}_{2}\right.$ and $\mathrm{CO})$ stations. A 24 hour period starting at 1600 the previous day up to 1600 on the current day was used to calculate the daily indicators for each pollutant. For $\mathrm{PM}_{10}$ and $\mathrm{SO}_{2}$ the indicators were daily means (24 hour averages) expressed as $\mu \mathrm{g} / \mathrm{m}^{3}$. For CO the highest 8 hour moving average expressed in ppm was used. The maximum hourly mean during the 24 hour period and expressed as $\mu \mathrm{g} / \mathrm{m}^{3}$ was used for $\mathrm{O}_{3}$ and $\mathrm{NO}_{2}$. All available monitoring stations were averaged to produce daily city wide concentrations of each pollutant.

Meteorological data were also collected for the same period and included daily measurements of temperature (mean, maximum, and minimum daily level in ${ }^{\circ} \mathrm{C}$ ) and humidity (mean, maximum, and minimum daily levels expressed as percentages).

\section{ANALYTICAL METHODS}

Linear regression with $\log$ transformed outcomes was used first to obtain a baseline or core model with potential confounders. The contribution of each term to the fit of the model was assessed by $F$ tests. After establishing these core models, Poisson regression was used to examine the contribution of air pollution variables to the prediction of daily admissions.

Long term temporal trends usually present in time series of health events were adjusted for by linear and quadratic functions of a continuous variable and indicators for years of the

Table 1 Descriptive statistics for air pollution, meteorological variables and hospital admission data, in São Paulo, Brazil, November 1992 to September 1994

\begin{tabular}{lllllllll}
\hline \multicolumn{7}{c}{ Percentiles } \\
\cline { 3 - 9 } & Mean $(S D)$ & Min & 5 & 25 & 50 & 75 & 95 & Max \\
\hline $\mathrm{PM}_{10}\left(\mu \mathrm{g} / \mathrm{m}^{3}\right)$ & $64.9(32.7)$ & 18.4 & 31.1 & 42.9 & 55.4 & 75.5 & 131.6 & 231.8 \\
$\mathrm{SO}_{2}\left(\mu \mathrm{g} / \mathrm{m}^{3}\right)$ & $18.3(9.0)$ & 3.2 & 7.6 & 11.9 & 16.6 & 22.2 & 35.8 & 61.1 \\
$\mathrm{NO}_{2}\left(\mu \mathrm{m} \mathrm{m}^{3}\right)$ & $174.3(101.3)$ & 26.0 & 62.0 & 108.8 & 151.7 & 210.0 & 388.0 & 692.9 \\
$\mathrm{CO}^{(\mathrm{ppm})}$ & $5.8(2.4)$ & 13.0 & 2.6 & 4.1 & 5.6 & 7.1 & 9.9 & 22.8 \\
$\mathrm{O}_{3}\left(\mu \mathrm{gg} / \mathrm{m}^{3}\right)$ & $63.4(38.1)$ & 4.6 & 12.9 & 35.2 & 57.3 & 85.5 & 136.2 & 194.8 \\
Temperature & $19.4(3.5)$ & 7.0 & 12.7 & 17.3 & 19.8 & 22.0 & 24.4 & 26.3 \\
Relative humidity & $77.6(10.6)$ & 42.0 & 57.0 & 72.9 & 79.1 & 85.1 & 92.2 & 98.0 \\
Respiratory <5 & $56.1(18.7)$ & 18 & 29 & 42 & 54 & 68 & 91 & 117 \\
Pneumonia <5 & $40.8(15.0)$ & 6 & 20 & 30 & 39 & 50 & 70 & 94 \\
Pneumonia <1 & $24.0(11.4)$ & 3 & 9 & 16 & 21 & 30 & 48 & 69 \\
Asthma ${ }^{\star}<5$ & $8.5(3.9)$ & 1 & 3 & 6 & 8 & 11 & 16 & 21 \\
\hline
\end{tabular}

${ }^{\star}$ Asthma and bronchitis.

Missing data for air pollutants: $\mathrm{PM}_{10}=22$ days $(3.2 \%), \mathrm{SO}_{2}=22(3.2 \%), \mathrm{NO}_{2}=340(48.6 \%)$, $\mathrm{CO}=25(3.6 \%), \mathrm{O}_{3}=68(9.7 \%)$ study. Seasonal and other cyclical variations were accounted for by the inclusion of sine and cosine waves spanning periods down to 2 months. Short term effects-such as day of the week, bank holidays, and strikes in public transport or in health services-were adjusted for by the inclusion of indicator variables.

To adjust for temperature, initially cross correlation functions of seasonally adjusted residuals were used to identify the best lags at which the effect of temperature was greatest on each series of hospital admissions. Plots of these residuals against measures of temperature at the appropriate lags were examined to help find the shape of the exposure-response relation and therefore aid the choice of appropriate transformations of temperature variables which would provide the best model fit. Functions with different shapes-such as linear, quadratic, two piece linear, three piece linear, and non-linear shapes-were constructed to allow for different patterns of the relation between temperature and hospital admissions. This procedure was an attempt to adjust for the effects of temperature on hospital admissions with sufficient flexibility for the different patterns of this relation but without overspecifying the model.

Single linear and quadratic terms were explored for the daily relative humidity and the one that provided the best fit as judged by $F$ tests was included in the final model regardless of the significance of the coefficient.

Spectral analysis and periodograms, plots of residuals, and of predicted values were used at each step to check the adequacy of the modelling and also to update the initial selection of variables used to control confounding. The partial autocorrelation function of the residuals were also examined to assess the presence of any remaining autocorrelation in the data. Simple Poisson regression models allowing for overdispersion or autoregressive log linear regression models with Poisson errors were used according to the presence or not of autocorrelation in the residuals. Regression coefficients (95\% confidence intervals (95\% CIs)) for each specific exposure were then obtained. All the statistical procedures were implemented in SAS with emphasis on the econometric and time series (ETS) module. ${ }^{22}$

\section{Results}

Descriptive statistics for the daily values of air pollution, meteorological variables, and hospital admission data are shown in table 1. Each air pollutant was unavailable for at least a few of the days covered by this study, but $\mathrm{NO}_{2}$ had a very high proportion (nearly half) of missing data. This was due to technical problems and occurred mainly during the last months of the study period, which were therefore, excluded from the analysis for that pollutant. The available data showed that concentrations of $\mathrm{NO}_{2}$ were above the recommended World Health Organisation (WHO) guideline ${ }^{23}$ of $190 \mu \mathrm{g} / \mathrm{m}^{3}$ on $>25 \%$ of the days. Other pollutants had only a few days above the recommended guideline concentrations. 
Table 2 Pearson correlation coefficients between air pollution variables in São Paulo, Brazil, November 1992 to September 1994

\begin{tabular}{lllll}
\hline & $\mathrm{SO}_{2}$ & $\mathrm{NO}_{2}$ & $\mathrm{CO}$ & $\mathrm{O}_{3}$ \\
\hline $\mathrm{PM}_{10}$ & 0.72 & 0.40 & 0.63 & $0.001^{\star}$ \\
$\mathrm{SO}_{2}$ & & 0.37 & 0.65 & $0.08^{\star}$ \\
$\mathrm{NO}_{2}$ & & & 0.35 & 0.25 \\
$\mathrm{CO}$ & & & & -0.16 \\
\hline
\end{tabular}

*Correlations not significant.

The Pearson correlation coefficients among air pollutants are presented in table 2 . As can be seen most air pollutants are positively correlated. However, whereas $\mathrm{PM}_{10}$ and $\mathrm{SO}_{2}$ had a relatively high correlation, $\mathrm{O}_{3}$ was not highly correlated with any other pollutant.

After decomposing the raw series of hospital admissions with spectral analysis and plotting the periodogram, the characteristic pattern of seasonality present in these data was observed. Large periodicities for periods around and above 1 year and 1 week were evident (fig 1 ).

In general, lagged effects of temperature seemed to have a greater effect than measures taken on the same day. For admissions from all respiratory causes and from pneumonia the effect of temperature was larger when lagged by 1 day, and for asthma a lag of 3 days provided the best fit. For pneumonia in infants $<1$ year old, measures of temperature on the same day provided the best fit.

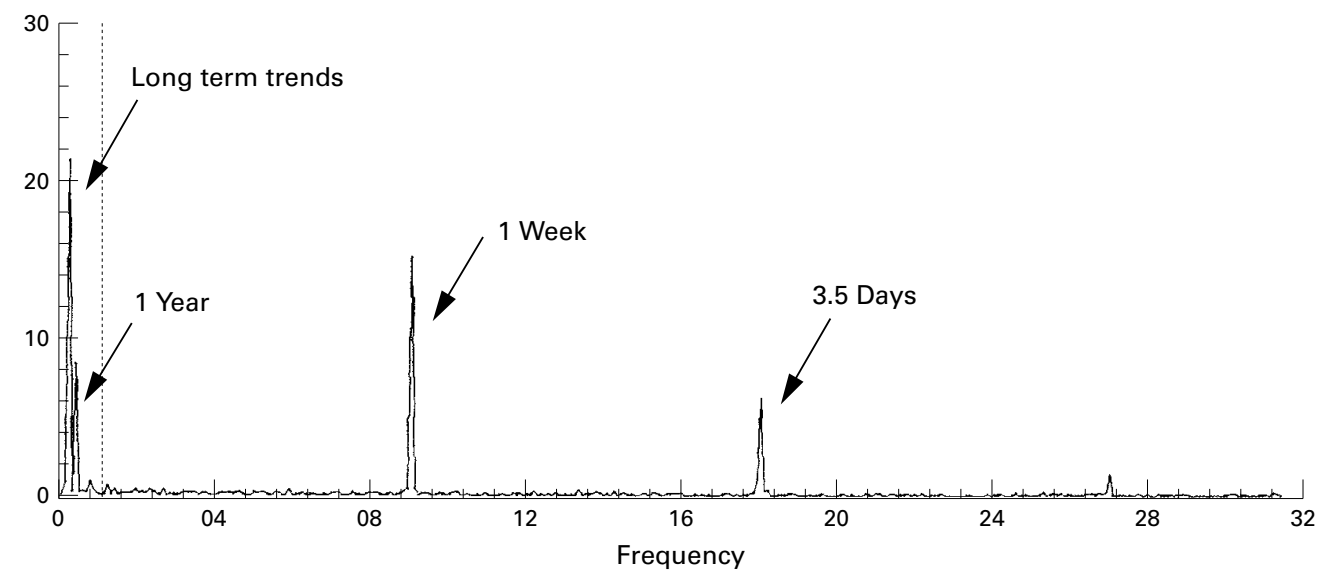

Figure 1 Periodogram of the residuals of unfiltered log transformed data for hospital admissions from all respiratory causes in children $<5$ years old. The vertical dotted line refers to a frequency equivalent to a period of 2 months.

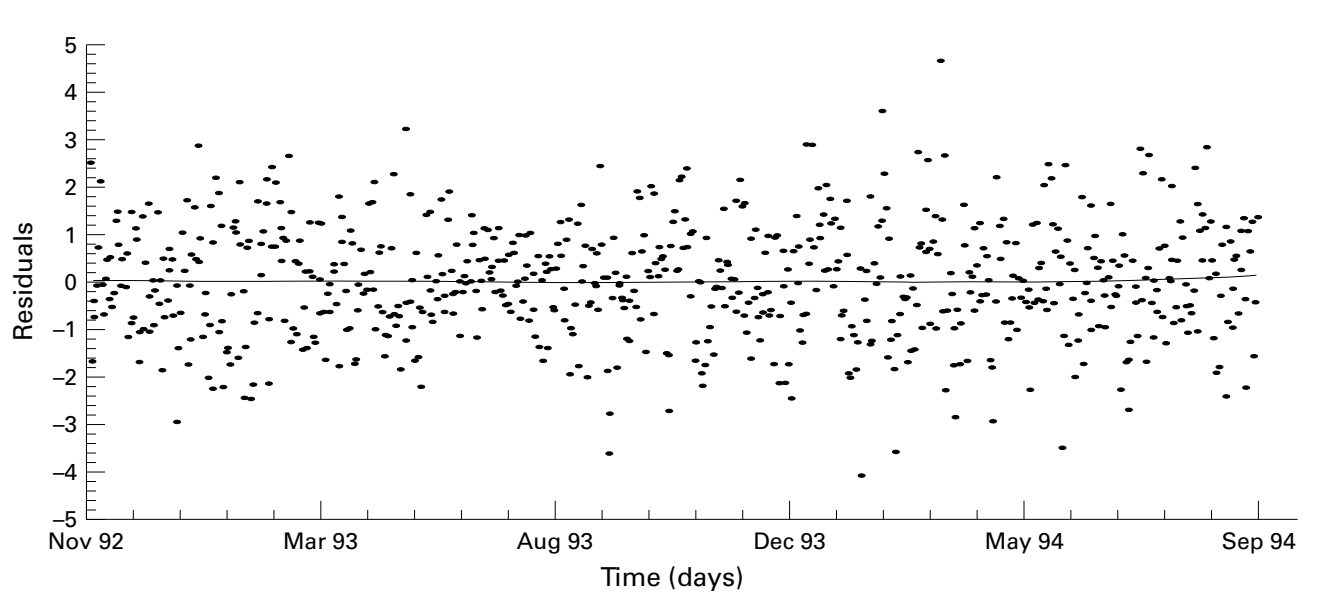

Figure 2 Plot of the residuals of admissions for all respiratory causes from the core model adjusting for long and short term temporal trends, plus meteorological variables versus time. A non-parametric smooth curve was plotted through the data to indicate any remaining seasonal variability in the data.

After performing all the adjustments for temporal, cyclical, and meteorological patterns, the residuals of the final adjusted models were plotted against the period to examine if there were signs of temporal and seasonal patterns still unaccounted for. As observed in the example of figure 2 the core model seems successful in controlling for all these patterns.

After all these adjustments, the residuals from the core model were then re-checked for the possibility of any remaining autocorrelation which would be adjusted for with autoregressive models. We found that some of the models had no remaining autocorrelation after the filtering procedures. Others had autocorrelation of first order but with a low coefficient.

Finally, the exposure variables were entered one at a time into the final core models produced for each outcome. Poisson regression models allowing for overdispersion, and when necessary, for autocorrelated errors were used. inative risks (RRs) were calculated for an in concentrations of each air pollutant. Daily variations in concentrations of all pollutants showed positive associations with hospital admissions for all respiratory diseases in children $<5$ years old. The coefficient estimate for $\mathrm{O}_{3}$ reached the significant 5\% level, whereas for $\mathrm{NO}_{2}$ it was of borderline significance (table 3). 
Table 3 Adjusted RRs of hospital admission for respiratory diseases in children $<5$ and $<1$ year old (RRs are for an increase from the 10th to the 90th percentile in daily concentrations of each pollutant)

\begin{tabular}{lllll}
\hline & All respiratory & Pneumonia & Pneumonia $<1$ & Asthma \\
\hline $\mathrm{PM}_{10}$ & $1.040(0.985-1.099)$ & $1.050(0.984-1.121)$ & $1.094(1.013-1.180)$ & $1.052 \dagger(0.923-1.198)$ \\
$\mathrm{SO}_{2}$ & $1.038^{\star}(0.983-1.096)$ & $1.024^{\star}(0.961-1.091)$ & $1.071(0.998-1.149)$ & $1.106 \dagger(0.981-1.247)$ \\
$\mathrm{NO}_{2}$ & $1.063(0.999-1.132)$ & $1.093(1.016-1.177)$ & $1.091(0.996-1.193)$ & $1.107 \dagger(0.940-1.300)$ \\
$\mathrm{O}_{3}$ & $1.054(1.003-1.107)$ & $1.076(1.014-1.142)$ & $1.070(0.993-1.152)$ & $1.011 \dagger(0.899-1.136)$ \\
$\mathrm{CO}$ & $1.017(0.971-1.065)$ & $1.015(0.961-1.071)$ & $1.035 \dagger(0.975-1.099)$ & $1.081(0.980-1.192)$ \\
\hline
\end{tabular}

*lag=1 day; +lag=2 day.

10th to 90th percentiles were: $\mathrm{PM}_{10}=98.1 \mu \mathrm{g} / \mathrm{m}^{3}, \mathrm{SO}_{2}=27.1 \mu \mathrm{g} / \mathrm{m}^{3}, \mathrm{NO}_{2}=319.4 \mu \mathrm{g} / \mathrm{m}^{3}, \mathrm{O}_{3}=119.6 \mu \mathrm{g} / \mathrm{m}^{3}, \mathrm{CO}=6.9 \mathrm{ppm}$.

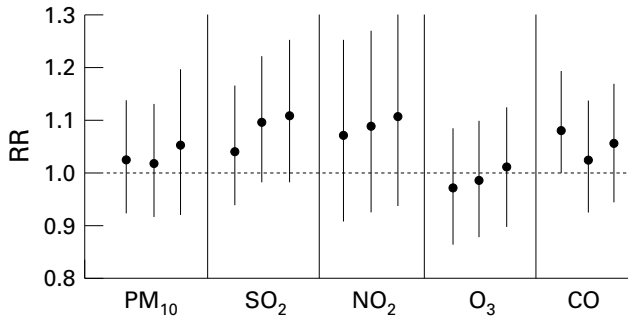

Figure 3 Relative risks (RR) (95\% CI) for admissions from asthma in children $<5$ years old for a change in daily concentrations of pollutants from the 10th to the 90th percentile. Effect at the same day (left), lagged 1 and 2 days (middle and right respectively).

The effects of other pollutants were also positive but not significant. The effects were larger for exposures on the same day for $\mathrm{PM}_{10}$, $\mathrm{NO}_{2}, \mathrm{O}_{3}$, and $\mathrm{CO}$ and on a lag of 1 day for $\mathrm{SO}_{2}$. As explained in the methods section, measures of air pollutants on a certain day already include one third of a day lag as measurements started at 1600 the previous day. An increase from the 10th to the 90th percentile in concentrations of $\mathrm{O}_{3}$ and $\mathrm{NO}_{2}$ corresponded to a $5 \%$ and $6 \%$ increase in admissions respectively for respiratory diseases in children $<5$ years old.

For more specific causes of respiratory admissions - such as pneumonia - in the children $<5$ year old, again all studied pollutants showed positive effect estimates. Moreover, the magnitude of the effects was usually higher than for admissions for all respiratory diseases although only $\mathrm{O}_{3}$ and $\mathrm{NO}_{2}$ reached significance. An increase in $\mathrm{NO}_{2}$ from the 10th to the 90 th percentile was associated with a $9 \%$ increase in hospital admissions for pneumonia in children $<5$ years old. For $\mathrm{O}_{3}$ this increase was estimated to be $8 \%$.

When analysing the admissions for pneumonia among infants (excluding neonatal cases) it was noted that the risk estimates for $\mathrm{PM}_{10}, \mathrm{CO}$, and $\mathrm{SO}_{2}$ were even higher than for all children $<5$ years old whereas for $\mathrm{NO}_{2}$ and $\mathrm{O}_{3}$ they were similar. The effect for $\mathrm{PM}_{10}$ was significant ( $9 \%$ for the 10th to the 90th percentile increase), and all the other pollutants except $\mathrm{CO}$ were of borderline significance.

It should be noted that the effects of exposure to air pollution on admissions for all respiratory causes and for pneumonia infec- tions were generally greater at lag zero (with exposures on the same day) for most pollutants, and lagged by 1 day for $\mathrm{SO}_{2}$. By contrast, for pneumonia admissions in infants $<1$ year old, $\mathrm{SO}_{2}$ showed a larger effect with measures on the same day, and $\mathrm{CO}$ when lagged by 2 days. The somewhat lower RRs shown for CO for all these outcomes should also be noted.

In the analysis of admissions for asthma and bronchitis, the lag with the strongest effect was, with the exception of CO, 2 days (fig 3), a different pattern from that evident for other respiratory diseases. The point estimates were higher than for admissions for all respiratory diseases combined for $\mathrm{SO}_{2}$ and $\mathrm{NO}_{2}$. For example, an increase from the 10th to the 90th percentile in concentrations of these two pollutants is associated with about an $11 \%$ increase in daily admissions. However, none of these coefficients were significant at the $5 \%$ level.

We then performed analyses in which the effect of each pollutant that was significant on its own in any of the models was examined with other pollutants (table 4). When both $\mathrm{O}_{3}$ and $\mathrm{PM}_{10}$ were considered in different models with $\mathrm{NO}_{2}$, their effect estimates increased by a third or more whereas $\mathrm{NO}_{2}$ showed reduced estimates. Moreover, when $\mathrm{O}_{3}$ and $\mathrm{PM}_{10}$ were included in the same model, $\mathrm{O}_{3}$ showed a decrease on its estimated coefficient whereas $\mathrm{PM}_{10}$ again showed an increase. Decreases in effect estimates for $\mathrm{NO}_{2}$ were larger when $\mathrm{PM}_{10}$ was present in the model.

In a model considering all three pollutants, $\mathrm{O}_{3}$ and $\mathrm{PM}_{10}$ still showed increases, although they were smaller, in their estimated effects but the estimate for $\mathrm{NO}_{2}$ decreased. Also, it has to be pointed out that estimates for $\mathrm{O}_{3}$ were either significant or of borderline significance in all multipollutant models. Similar results were found for other outcomes.

To examine whether the association between air pollutants and hospital admissions for children could vary by season, even after adjustments for seasonality and other weather related variables, interaction terms between season and single air pollutants were introduced into the model for all respiratory admissions in children $<5$ years old. Due to the weather charac-

Table 4 Adjusted RRs of hospital admission for respiratory diseases in children $<5$ in single and multipollutant models (RRs are for an increase from the 10th to the 90th centile in daily concentration of each pollutant)

\begin{tabular}{llllll}
\hline & Single pollutant model & $\begin{array}{l}\text { Two pollutant model } \\
\left(\mathrm{NO}_{2} \text { and } \mathrm{O}_{3}\right)\end{array}$ & $\begin{array}{l}\text { Two pollutant model } \\
\left(P M_{10} \text { and } \mathrm{NO}_{2}\right)\end{array}$ & $\begin{array}{l}\text { Two pollutant model } \\
\left(P M_{10} \text { and } \mathrm{O}_{3}\right)\end{array}$ & Three pollutant model \\
\hline $\mathrm{PM}_{10}$ & $1.040(0.985-1.099)$ & & $1.058(0.962-1.160)$ & $1.058(0.993-1.128)$ & $1.044(0.946-1.151)$ \\
$\mathrm{NO}_{2}$ & $1.063(0.999-1.132)$ & $1.050(0.985-1.120)$ & $1.043(0.972-1.119)$ & & $1.035(0.963-1.113)$ \\
$\mathrm{O}_{3}$ & $1.054(1.003-1.107)$ & $1.071(1.008-1.139)$ & & $1.045(0.994-1.099)$ & $1.065(0.999-1.134)$ \\
\hline
\end{tabular}




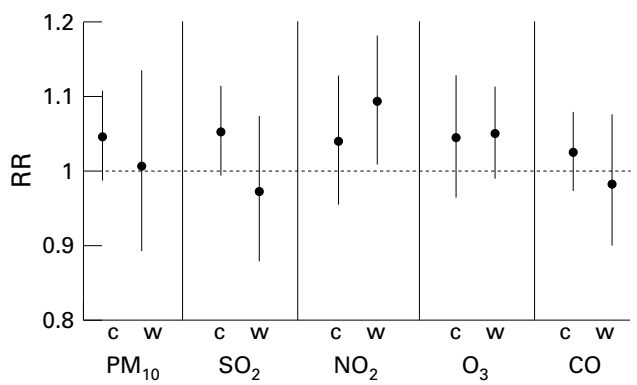

Figure 4 Relative risks (95\% CI) for respiratory admissions in children $<5$ years of age for an increase from the 10th to the 90th percentile in concentrations of pollutants by season ( $c=$ cool and w=warm season).

teristics of São Paulo it was decided to explore the effect modification by season, dividing the calendar year into only two categories-cool and warm. Most of the pollutants presented greater effect estimates during the cool season (May-October), with the exception of $\mathrm{NO}_{2}$, the effect of which was higher during the warm season (fig 4). However, it has to be pointed out that the interactions of each air pollutant and season were not significant at the $5 \%$ level.

\section{Discussion}

This study found indications that current ambient air pollution concentrations in the city of São Paulo have short term adverse effects on children's respiratory morbidity assessed through admissions to hospitals. Although use of health services has been previously used in time series studies of air pollution, there are specific issues that deserve discussion.

One concern is the possibility of selection and information bias. Private hospitals covered by private health insurance were not part of the information system used in this study. Thus, the wealthier portions of the population are likely to be underrepresented. Also, admission to the hospital can be affected by the availability of beds, which may depend on some independent event acting possibly on a different timescale. ${ }^{24}$

However, although selected, this study population acts as its own control in a time series study, minimising the possibility of bias. The possible constraints in the availability of hospital beds were also not expected to be correlated with concentrations of air pollutants. Thus, neither aspect is likely to bias this time series study.

Another concern is the quality of the information on each hospital admission, especially the one related to the diagnosis. A previous study has examined this issue comparing the information provided by the computerised files used here against recorded information of each patient available at the hospitals. ${ }^{25}$ They found considerable agreement, especially for diagnosis and demographic variables. Moreover, it is not expected that the quality of the information on each admission will vary on a daily basis, nor will it be correlated with air pollution.

In summary, this study found that when air pollution concentrations in São Paulo were increased on the same day, or on the previous day, an increase in the admissions of children to hospital was found. These associations were found for admissions for all respiratory diseases and for pneumonia infections in children $<5$ years old and infants. Consistently, effects for pneumonia were greater than for all respiratory diseases combined. Also, effects on infants $<1$ year old also presented higher estimates. There was also some weaker evidence of similar associations with admissions for asthma.

Associations between hospital admissions for respiratory diseases and air pollution have already been reported. $.^{19}{ }^{21} 26-33$ However, most of these studies were conducted in developed countries and refer to hospital admissions of adults. Only few such studies considered the issue of effects of air pollution on hospital admissions of children, and even fewer in a developing country.

Our findings accord with this limited epidemiological literature. However, the size of the effects found in this study were somehow smaller than most published studies. A recent meta-analysis reported RRs of 1.06 and 1.13 for a $100\left(\mu \mathrm{g} / \mathrm{m}^{3}\right)$ increase in concentrations of $\mathrm{O}_{3}$ and $\mathrm{PM}_{10}$ respectively, ${ }^{34}$ whereas in the present study we found an RR of 1.04 for the same increase in each pollutant. Studies on mortality relative to air pollution carried out in developing countries have also reported smaller effects than the ones usually found in the United States or Europe. ${ }^{35}{ }^{36}$ It should be noted that a smaller effect of air pollution on mortality has also been described in an as yet unpublished study conducted in São Paulo.

Reasons for such differences deserve further consideration. We might speculate that differences in weather characteristics between most developed and developing countries could influence the composition of the pollution mix and therefore, its effect on human health. Another possibility is that populations in developing countries, especially vulnerable groups such as young children, usually experience other competing causes of morbidity, which are together more important than air pollution. Therefore, population susceptibility to the effects of exposure to air pollution might be different between developed and developing countries.

This study also found that effect estimates for most pollutants were higher for asthma admissions than for other causes of respiratory diseases. However, the $95 \%$ CIs were much wider and none of these relations reached significance.

Previous studies relating air pollution to admissions to hospital for asthma or other wheezy conditions have shown conflicting results even when using identical methodology. ${ }^{32} 3738$ However, there are some studies reporting positive associations between $\mathrm{O}_{3}$ or $\mathrm{PM}_{10}$ and hospital admissions or emergency room visits for asthma in children. ${ }^{21}{ }^{39-41}$

The failure to find a significant association between air pollution and asthma admissions in this study might be attributed to insufficient power. The median daily number of admissions 
for asthma and bronchitis was only eight compared with 39 for pneumonia.

Also, this study was concerned with acute effects of air pollution on exacerbating asthma attacks, and not the initiation of asthma. However, admissions to hospital would essentially reflect the more severe cases of asthma. Less severe cases are very likely to be larger in number, to be treated at the emergency room, and be discharged home. Such cases, therefore, are not included in the hospital admissions dataset.

It could also be that air pollution has relatively little effect on asthma admissions. Recent studies have shown that rapid increases in attendance with asthma in hospitals (asthma epidemics) are associated with grass pollen released before and during thunderstorms and not with air pollution. ${ }^{42-44}$

In our study we found associations between admissions for all respiratory diseases and for pneumonia with concentrations of $\mathrm{PM}_{10}, \mathrm{NO}_{2}$, and $\mathrm{O}_{3}$. Similar associations have been reported for $\mathrm{SO}_{2},{ }^{26}{ }^{27} \mathrm{CO},{ }^{28}$ and $\mathrm{NO}_{2},{ }^{29}$ but more consistently for $\mathrm{O}_{3}{ }^{26-28}{ }^{30-32}$ and $\mathrm{PM}_{10} \cdot{ }^{19} 212831-33$

However, the question of which pollutant or pollutants are the ones more strongly associated with health effects is not yet resolved. Previous attempts to isolate the individual effects of different air pollutants proved to be a difficult task ${ }^{45}$ mainly due to the high collinearity usually present among pollutants in the air.

In this study the correlation among pollutants, although positive, was not particularly high. Also, $\mathrm{O}_{3}$ was poorly correlated with most other pollutants. We tried to separate the effects of the different pollutants exploring models with more than one pollutant and found that the effects of $\mathrm{PM}_{10}, \mathrm{NO}_{2}$, and $\mathrm{O}_{3}$ changed when they were included in pairs or all together in the same model. The coefficient estimate for $\mathrm{PM}_{10}$, and especially for $\mathrm{O}_{3}$ showed a more stable behaviour than the estimates for $\mathrm{NO}_{2}$.

To interpret such results we need to consider that if one pollutant was acting only as a proxy for the other with no contribution of its own, it would be expected that its effect would become very small in a two pollutant model whereas that of the other would remain unchanged. The large fall in the magnitude of the coefficient estimate for $\mathrm{NO}_{2}$ suggests that this pollutant is less likely to be acting as a risk factor for hospital admissions in children. It is possible that $\mathrm{O}_{3}$ and $\mathrm{PM}_{10}$ have independent effects on the respiratory admission of children in the city of São Paulo.

However, it should be pointed out that measurements of $\mathrm{NO}_{2}$ showed the highest proportion of missing data for the analysis of hospital admissions. Also, the analyses for the multipollutant models were restricted to the periods when $\mathrm{NO}_{2}$ was available. But more importantly, pollutants in the air constitute a complex mixture, the components of which may interact with one another in their effects on human health.

The fact that any of the pollutants found to be associated with hospital admissions can be simply acting as a proxy for another or just indicators of a complex mixture of air pollutants make it difficult to conclude that a single component of air pollution is causally associated with adverse effects on human health.

Taking these points into account, this study indicates that concentrations of outdoor air pollution have observable effects on respiratory morbidity in a special susceptible populationchildren $<5$ years of age. Although such effects seem to be smaller than those previously reported elsewhere they still have an important impact on public health due to the large population potentially exposed in a city like São Paulo. Future studies should attempt to confirm these findings and explore in more depth the differences in magnitude of effects among different populations.

Early versions of this manuscript have received helpful comments from $\mathrm{Mr}$ Stephen Bremner. This work was supported by grant number 201310/91-0 from the Brazilian Research Council (CNPq).

1 Grahan N. The epidemiology of acute respiratory infections in children and adults: a global perspective. Epidemiol Rev 1990;12:149-78.

2 Garenne M, Ronsmans C, Campbell H. The magnitude of mortality from acute respiratory infections in children under 5 years in developing countries. World Health Stat $Q$ 1992;45:180-91.

3 World Health Organization. 1991: World health statistics annual. Geneva. WHO, 1992 .

4 Schwartz J. Total suspended particulate matter and daily mortality in Cincinnati, Ohio. Environ Health Perspect mortality in Cin

5 Pope CA, Schwartz J, Ransom MR. Daily mortality and $\mathrm{PM}_{10}$ pollution in Utah Valley. Arch Environ Health $1992 ; 47: 211-7$

6 Schwartz J, Dockery DW. Increased mortality in Philadelphia associated with daily air pollution concentrations. $\mathrm{Am}$ Rev Respir Dis 1992;145:600-4.

7 Schwartz J. What are people dying of on high air pollution days? Environ Res 1994;64:26-35.

8 Anderson HR, Ponce de Leon A, Bland JM, et al. Air pollution and daily mortality in London: 1987-92. BMF 1996;312:665-9.

9 Spektor DM, Hofmeister VA, Artaxo P, et al. Effects of heavy industrial pollution on respiratory function in the children of Cubatao, Brazil: a preliminary report. Environ Health Perspect 1991;94:51-4.

10 Peters A, Goldstein IF, Beyer U, et al. Acute health effects of exposure to high levels of air pollution in eastern Europe. Am 7 Epidemiol 1996;144:570-81.

11 Hoek G, Fischer P, Brunekreef B, et al. Acute effects of ambient ozone on pulmonary function of children in The Netherlands. Am Rev Respir Dis 1993;147:111-7.

12 Pope CA, Dockery DW. Acute health effects of $\mathrm{PM}_{10}$ pollution on symptomatic and asymptomatic children. Am Rev Respir Dis 1992;145:1123-8.

13 Ransom MR, Pope CA. Elementary school absences and $\mathrm{PM}_{10}$ pollution in Utah Valley. Environ Res 1992;58:20419.

14 Romieu I, Lugo MC, Velasco SR, et al. Air pollution and school absenteeism among children in Mexico City. Am 7 Epidemiol 1992;136:1524-31.

15 Braun Fahrlander C, Ackermann Liebrich U, Schwartz J, et $a l$. Air pollution and respiratory symptoms in preschool children. Am Rev Respir Dis 1992;145:42-7.

16 Jaakkola JJ, Paunio M, Virtanen M, et al. Low-level air pollution and upper respiratory infections in children. $A m \mathcal{F}$ Public Health 1991;81:1060-3.

17 Sobral HR. Air pollution and respiratory diseases in children in Sao Paulo, Brazil. Soc Sci Med 1989;29:959-64.

18 Dockery DW, Speizer FE, Stram DO, et al. Effects of inhalable particles on respiratory health of children. Am Rev Respir Dis 1989;139:587-94.

9 Pope CAII. Respiratory hospital admissions associated with $\mathrm{PM}_{10}$ pollution in Utah, Salt Lake, and Cache Valleys. Arch Environ Health 1991;46:90-7.

$20 \mathrm{Xu} \mathrm{X,} \mathrm{Li} \mathrm{B,} \mathrm{Huang} \mathrm{H.} \mathrm{Air} \mathrm{pollution} \mathrm{and} \mathrm{unscheduled} \mathrm{hos-}$ pital outpatient and emergency room visits. Environ Health Perspect 1995;103:286-9

21 Pope CA. Respiratory disease associated with community air pollution and a steel mill, Utah Valley. Am f Public Health 1989;79:623-8.

22 SAS Institute. SAS/ETS software: applications guide 1. Time series modelling and forecasting, financial reporting, and loan analysis, version 6. Cary, NC: SAS Institute, 1991.

23 CETESB. Relatorio de Qualidade do Ar no Estado de Sao Paulo-1995. Sao Paulo: Companhia de Tecnologia de Saneamento Ambiental, 1995. 
24 Bennett AE. Limitations of the use of hospital statistics as an index of morbidity in environmental studies. 7 Air Pollut

25 Veras C, Martins M. Confiabilidade dos dados nos formulários de Autorização de Internação Hospitalar (AIH). Cad Saude Publ 1994;10:339-55.

26 Bates DV, Sizto R. Relationship between air pollutant levels and hospital admissions in Southern Ontario. Can F Public Health 1983;74:117-22.

27 Burnett RT, Dales RE, Raizenne ME, et al. Effects of low ambient levels of ozone and sulfates on the frequency of respiratory admissions to Ontario hospitals. Environ Res 1994;65:172-94.

28 Burnett RT, Brook JR, Yung WT, et al. Association between ozone and hospitalization for respiratory diseases in 16 Canadian cities. Environ Res 1997;72:24-31.

29 Walters S, Phupinyokul M, Ayres J. Hospital admission rates for asthma and respiratory disease in the West Midlands: their relationship to air pollution levels. Thorax 1995;50: 948-54.

30 Ponce de Leon A, Anderson HR, Bland JM, et al. Effects of air pollution on daily hospital admissions for respiratory disease in London between 1987-88 and 1991-2. F Epidemiol Community Health 1996;50(suppl 1):s63-70.

31 Schwartz J. Air pollution and hospital admissions for the elderly in Birmingham, Alabama. Am $\mathcal{F}$ Epidemiol 1994 139:589-98.

32 Schwartz J. Air pollution and hospital admissions for the elderly in Detroit, Michigan. Am 7 Respir Crit Care Med 1994;150:648-55.

33 Schwartz J. Air pollution and hospital admissions for respiratory disease. Epidemiology 1996;7:20-8.

34 Schwartz J. Health effects of air pollution from traffic: ozone and particulate matter. In: Fletcher T, McMichael AJ, eds. Health at the crossroads. Transport policy and urban health. Chichester, England: John Willey 1997:61-86.

35 Borja Aburto VH, Loomis DP, Bangdiwala SI, et al. Ozone, suspended particulates, and daily mortality in Mexico City Am f Epidemiol 1997;145:258-68.
36 Ostro B, Sanchez JM, Aranda C, et al. Air pollution and mortality: results from a study of Santiago, Chile. $\mathcal{F}$ Expo Anal Environ Epidemiol 1996;6:97-114.

37 Dab W, Medina S, Quenel P, et al. Short term respiratory health effects of ambient air pollution: results of the APHEA project in Paris. $\mathcal{F}$ Epidemiol Community Health 1996;50 (suppl 1):s42-6.

38 Schouten JP, Vonk JM, de Graaf A. Short term effects of air pollution on emergency hospital admissions for respiratory disease: results of the APHEA project in two major cities in The Netherlands, 1977-89. F Epidemiol Community Health 1996;50(suppl 1):s22-9.

39 Romieu I, Meneses F, Sienra Monge JJ, et al. Effects of urban air pollutants on emergency visits for childhood asthma in Mexico City. Am f Epidemiol 1995;141:546-53.

40 Buchdahl R, Parker A, Stebbings T, et al. Association between air pollution and acute childhood wheezy episodes: prospective observational study. BMF 1996;312: $661-5$.

41 Schwartz J, Slater D, Larson TV, et al. Particulate air pollution and hospital emergency room visits for asthma in Seattle. Am Rev Respir Dis 1993;147:826-31.

42 Celenza A, Fothergill J, Kupek E, et al. Thunderstorm associated asthma: a detailed analysis of environmental factors. BMF 1996;312:604-7.

43 Davidson AC, Emberlin J, Cook AD, et al. A major outbreak of asthma associated with a thunderstorm: experience of accident and emergency departments and patients' characteristics. Thames Regions Accident and Emergency Trainees Association. BMF 1996;312:601-4.

44 Bauman A. Asthma associated with thunderstorms. BMF 1996;312:590-1.

45 Health Effects Institute. Particulate air pollution and daily mortality: analyses of the effects of weather and multiple air pollutants. The phase i. ation project. Cambridge, MA: Health Effects Institute, 1997 .

\section{Vancouver style}

All manuscripts submitted to Occup Environ Med should conform to the uniform requirements for manuscripts submitted to biomedical journals (known as the Vancouver style.)

Occup Environ Med, together with many other international biomedical journals, has agreed to accept articles prepared in accordance with the Vancouver style. The style (described in full in the $\mathcal{F} A M A[1]$ ) is intended to standardise requirements for authors, and is the same as in this issue.

References should be numbered consecutively in the order in which they are first mentioned in the text by Arabic numerals on the line in square brackets on each occasion the reference is cited (Manson[1] confirmed other reports[2][3][4][5]). In future references to papers submitted to Occup Environ Med should include: the names of all authors if there are three or less or, if there are more, the first three followed by et al; the title of journal articles or book chapters; the titles of journals abbreviated according to the style of Index Medicus; and the first and final page numbers of the article or chapter. Titles not in Index Medicus should be given in full.

Examples of common forms of references are:

1 International Committee of Medical Journal Editors. Uniform requirements for manuscripts submitted to biomed journals. ЭAMA 1993;269:2282-6.

2 Soter NA, Wasserman SI, Austen KF. Cold urticaria: release into the circulation of histmaine and eosinophil chemotactic factor of anaphylaxis during cold challenge. chemotactic factor of anaphylax

3 Weinstein L, Swartz MN. Pathogenic properties of invadWeinstein L, Swartz MN. Pathogenic properties of invad-
ing micro-organisms. In: Sodeman WA Jr, Sodeman WA, ing micro-organisms. In: Sodeman WA Jr, Sodeman WA,
eds. Pathologic physiology, mechanisms of disease. Philadeleds. Pathologic physiology, mechanisms
phia: W B Saunders, 1974:457-72. 